\title{
Assessment of Contemporary Antarctic GIA Models Using High-Precision GPS Time Series
}

\author{
Wenhao Li ${ }^{1,2}$, Fei Li ${ }^{2,3}$, C.K. Shum ${ }^{4,5}{ }^{(0)}$, Chanfang Shu ${ }^{1,6}$, Feng Ming ${ }^{7}$, Shengkai Zhang ${ }^{2, *} \mathbb{D}$, Qingchuan Zhang ${ }^{2}$ \\ and Wei Chen ${ }^{4}$
}

check for updates

Citation: Li, W.; Li, F.; Shum, C.; Shu, C.; Ming, F.; Zhang, S.; Zhang, Q.;

Chen, W. Assessment of Contemporary Antarctic GIA Models Using High-Precision GPS Time Series. Remote Sens. 2022, 14, 1070. https://doi.org/10.3390/rs14051070

Academic Editors: Xiaoxing He, Jean-Philippe Montillet, Gaël Kermarrec, Rui Fernandes and Feng Zhou

Received: 21 January 2022

Accepted: 17 February 2022

Published: 22 February 2022

Publisher's Note: MDPI stays neutral with regard to jurisdictional claims in published maps and institutional affiliations.

Copyright: (C) 2022 by the authors. Licensee MDPI, Basel, Switzerland. This article is an open access article distributed under the terms and conditions of the Creative Commons Attribution (CC BY) license (https:// creativecommons.org/licenses/by/ $4.0 /)$.
1 School of Geomatics Science and Technology, Nanjing Tech University, Nanjing 211816, China; wh_li@whu.edu.cn (W.L.); shuchanfang@njtech.edu.cn (C.S.)

2 Chinese Antarctic Center of Surveying and Mapping, Wuhan University, Wuhan 430079, China; fli@whu.edu.cn (F.L.); zqc@whu.edu.cn (Q.Z.)

3 State Key Laboratory of Information Engineering in Surveying, Mapping and Remote Sensing, Wuhan University, Wuhan 430079, China

4 Institute of Geodesy and Geophysics, Chinese Academy of Sciences, Wuhan 430010, China; ckshum@osu.edu (C.K.S.); chen.8889@osu.edu (W.C.)

5 Division of Geodetic Science, School of Earth Sciences, Ohio State University, Columbus, OH 43210, USA

6 State Key Laboratory of Geo-Information Engineering and Key Laboratory of Surveying and Mapping Science and Geospatial Information Technology of MNR, CASM, Beijing 100036, China

7 State Key Laboratory of Geo-Information Engineering, Xi'an Institute of Surveying and Mapping, Xi'an 710054, China; geodesy_xd@163.com

* Correspondence: zskai@whu.edu.cn

\begin{abstract}
Past redistributions of the Earth's mass resulting from the Earth's viscoelastic response to the cycle of deglaciation and glaciation reflect the process known as glacial isostatic adjustment (GIA). GPS data are effective at constraining GIA velocities, provided that these data are accurate, have adequate spatial coverage, and account for competing geophysical processes, including the elastic loading of ice/snow ablation/accumulation. GPS solutions are significantly affected by common mode errors (CMEs) and the choice of optimal noise model, and they are contaminated by other geophysical signals due primarily to the Earth's elastic response. Here, independent component analysis is used to remove the CMEs, and the Akaike information criterion is used to determine the optimal noise model for 79 GPS stations in Antarctica, primarily distributed across West Antarctica and the Antarctic Peninsula. Next, a high-resolution surface mass variation model is used to correct for elastic deformation. Finally, we use the improved GPS solution to assess the accuracy of seven contemporary GIA forward models in Antarctica. The results show that the maximal GPS crustal displacement velocity deviations reach $4.0 \mathrm{~mm} \mathrm{yr}^{-1}$, and the mean variation is $0.4 \mathrm{~mm} \mathrm{yr}^{-1}$ after removing CMEs and implementing the noise analysis. All GIA model-predicted velocities are found to systematically underestimate the GPS-observed velocities in the Amundsen Sea Embayment. Additionally, the GPS vertical velocities on the North Antarctic Peninsula are larger than those on the South Antarctic Peninsula, and most of the forward models underestimate the GIA impact on the Antarctic Peninsula.
\end{abstract}

Keywords: GPS; Antarctica; common mode error; noise model; GIA

\section{Introduction}

Glacial isostatic adjustment (GIA) is a process by which the solid Earth viscoelastically responds to the cycle of glaciation and deglaciation. GIA induces three-dimensional crustal displacements and global changes in the geoid, thereby varying regional sea level patterns; the corresponding increases and decreases in the ice load affect the gravitational field, Earth's rotation, and induce stress changes [1-4]. GIA-induced Earth surface velocities can be computed using forward or assimilated global GIA models, the results of which 
are constrained by sea level (sediment) records, 1D or 3D Earth rheology models, and the Earth's gravity and rotation [5].

Large differences persist in the GIA predictions for Antarctica owing to the large uncertainties in forward models, due primarily to our inadequate knowledge of the deglaciation history/extent and the Earth's rheology. At present, the 1D and 3D global GIA models and (in particular) the regional Antarctic GIA model are not fully understood [6]. Nevertheless, GIA can redistribute the mass of the within Earth's interior, which changes the Earth's gravitational field. Therefore, to estimate changes in surface mass (for example, ice sheet mass), GIA signals must be deduced from satellite gravity signals [7]. GIA is the largest error source at present, hindering the use of Gravity Recovery And Climate Experiment (GRACE/GRACE-FO) satellite gravimetry data to estimate the large-scale Antarctic ice sheet mass balance $[6,8]$. As a result, geodetic data-driven regionally inverted models, e.g., GIA models generated by assimilating GRACE, Global Positioning System (GPS), and other geodetic data or combining GRACE and satellite (laser) altimetry (ICESat) data, have been used [9-12] to correct for the effects of GIA on GRACE data.

Long-term GPS sites on bedrock can record vertical land motions (VLMs), which have been widely used to constrain GIA-induced uplift $[13,14]$ and as a data-driven approach to directly solve for the GIA effect [15]. Accurate GPS velocity solutions are usually affected by two factors: common mode errors (CMEs) and the selection of the optimal noise model (ONM). Therefore, when using the GPS velocity field to assess or extract GIA signals, we must filter or remove CMEs and confirm that the correct ONM is being used for data processing. CMEs are thought to be related to the spatiotemporal distributions of unmodeled signals and errors, including environmental and geophysical loading effects (atmospheric, nontidal, hydrological, etc.) and systematic errors [16]. The detrimental effects of these errors can be effectively reduced after properly filtering the data.

Stacking was first introduced by [17] to minimize the CMEs of GPS time series in southern California. However, we cannot quantitatively describe the physical mechanism and effect of CMEs over an adequately dense spatial scale. The authors of [16] used principal component analysis (PCA) to analyze 5-year GPS time series in southern California. Subsequently, many researchers have applied PCA and modified PCA methods to remove CMEs from GPS time series [18-21]. However, the PCA methods used to extract CMEs are usually considered to retain colored noise [16,22]. In addition, the PCA technique is based on second-order statistics and hence cannot take full advantage of higher-order statistics. Therefore, PCA filtering results in probable data contamination when applied to non-Gaussian-distributed GPS time series.

Relative to PCA, independent component analysis (ICA) can fully utilize higher-order statistics to exploit the non-Gaussian distributions of GPS time series [23]. Ming et al. [24] adopted ICA to investigate the time series from 259 GPS stations in China. Li et al. (2019) compared the filtering results of Antarctica GPS residual time series derived from PCA and ICA and found that ICA is better than PCA [25]. Considering the shortcomings of stacking and PCA filtering, we apply ICA to better extract the CMEs from GPS time series in Antarctica.

The noise model is another important factor that can affect the accuracy of GPSderived velocities [26]. Previous studies have shown that GPS time series contain not only white noise (WN) but also colored noise, e.g., flicker noise (FN) and random walk noise (RW) [27-29]. If the effects of colored noise are ignored, the uncertainty in the GPS velocity could be overestimated by a factor of four or even one order of magnitude higher than the signal amplitude [22]. Furthermore, for Antarctica, which spans a vast spatial area featuring complex terrain, it is neither reasonable nor effective to model all GPS station time series with one noise model. Consequently, in this paper, we adopted five noise models to confirm the ONM for GPS time series in Antarctica: white noise plus power law noise (WN + PL), white noise plus random walk noise ( $\mathrm{WN}+\mathrm{RW})$, white noise plus flicker noise $(\mathrm{WN}+\mathrm{FN})$, white noise plus flicker noise plus random walk noise $(\mathrm{WN}+\mathrm{FN}+\mathrm{RW})$, and white noise plus random walk noise plus generalized Gauss-Markov noise (WN + RW + GGM). 
In addition, the present-day ice sheet mass balance affects the instantaneous response of the solid Earth in the long term, and the signal of this response can be captured in GPS time series. The elastic response caused by the present-day ice mass loading may be an order of magnitude larger than the potential GIA-induced viscoelastic signal, and the viscoelastic signals from current changes in the ice mass loading can reach a few centimeters per year [30,31]. It is thus highly important to correct for the effects of elastic deformation due to ice and a variety of other geophysical sources when assessing the accuracy or performance of GIA models in Antarctica. Martín-Español et al. (2016) used elastic loading-corrected GPS vertical velocities in Antarctica over the period 2009-2014 to assess eight GIA models, including forward and inverse methods, and they found that the GPS uplift rates over specific regions characterized by reduced mantle viscosities and a relatively thin lithosphere were systematically underestimated [32]. Liu et al. (2018) applied ICA and PCA to the time series from 53 GPS stations from 2010 to 2014 and used the white noise plus power law (PL) noise model to estimate GPS velocities; after correcting for the effects of elastic loading, they assessed the consistencies of four GIA models with GPS-observed vertical velocities and discovered that their agreement generally improved after spatiotemporal filtering [33]. However, Martín-Español et al. (2016) did not perform filtering, and both Martín-Español et al. (2016) and Liu et al. (2018) considered only one noise model; moreover, there is no uniform criterion to consider the effects of CMEs and noise models. Therefore, a quantitative study of these effects on GPS velocity estimates and GIA assessments is needed.

In this paper, we employed a dataset describing the surface elevation change (SEC) of the Antarctic ice sheet covering a much longer data span than used in previous studies [34]. We first processed data from long-term and continuous GPS bedrock stations, mostly located in West Antarctica (WA) and the Antarctic Peninsula (AP), for displacements or velocities. Then, we analyzed the GPS solutions for the impacts of CMEs and tested five noise models. After that, we assessed the accuracy and consistency of seven contemporary GIA models for Antarctica: ICE-6G (VM5a) [13,14], ICE-5G (VM2_L90) [3,5], WANG [1], W12a [34,35], Geruo13 [36], IJ05-R2 [2], and Paulson07 [37]. In particular, the Geruo13 model of the spherical harmonic (SH) degree and order and Gaussian filtering radii: (a) truncated to SH degree and order 100 and no Gaussian filtering; (b) truncated to SH degree and order 60 and Gaussian filtering with a $200 \mathrm{~km}$ radius; and (c) truncated to SH degree and order 40 and Gaussian filtering with a $500 \mathrm{~km}$ radius. The IJ05-R2 model consisted of two various outputs based on different parameters of the Earth model: (a) a lithospheric thickness of $65 \mathrm{~km}$ and lower mantle viscosity of $1.5 \times 10^{21} \mathrm{~Pa} \cdot \mathrm{s}$ and (b) a lithospheric thickness of $115 \mathrm{~km}$ and a lower mantle viscosity of $4 \times 10^{21} \mathrm{~Pa} \cdot \mathrm{s}$. In this paper, we used the Geruo13 model complete to SH degree and order 100 and the IJ05-R2 model with a lithospheric thickness of $65 \mathrm{~km}$ and a lower mantle viscosity of $1.5 \times 10^{21} \mathrm{~Pa} \cdot \mathrm{s}$. The GIA models information is provided in Table S1.

The remainder of this paper is organized as follows. In Section 2, the data processing framework and methodology are briefly reviewed. The results of processing the GPS data and assessing the GIA models are discussed in Section 3. In Section 4, we discuss the assessment results for different regions. The conclusions of our findings are presented in Section 5.

\section{Materials and Methods}

\subsection{GPS Data}

The GPS time series were downloaded from the Nevada Geodetic Laboratory (NGL). GPS time series were processed by the GIPSY OASIS II software at the Jet Propulsion Laboratory (JPL), and the JPL's final orbit products were used in the time series solution. Precise point positioning to ionospheric-free carrier phase and pseudorange data were used. The Global Mapping Function was applied to model tropospheric refractivity, with tropospheric wet zenith delay and horizontal gradients estimated as stochastic randomwalk parameters every $5 \mathrm{~min}$ [38]. Coefficients were used to compute ocean loading for the site 
motion model, for which the FES2004 tidal model was applied, and ocean loading was also computed in the CM frame. Finally, ambiguity resolution was applied to double differences of the estimated one-way bias parameters [39] using the wide lane and phase bias (WLPB) method, which phase-connects individual stations to IGS stations in common view [40]. The station coordinates were converted to the IGS08 frame using daily 7-parameter transformations. Based on the distribution and integrity of the GPS time series, we selected 79 GPS stations covering the time span from 8 February 2010 to 23 June 2017; the details of GPS stations are presented in Table S1. The average proportion of missing data of our time series was $25.54 \%$. Figure 1 shows the locations of the 79 GPS stations in Antarctica. We used the interquartile range (IQR) to remove points more than $3^{*} \mathrm{IQR}$ away from the median [41], and then we subtracted the trends and annual and semiannual terms to form the residual time series using Hector software [42] (the offset was estimated based on the information at http:/ / geodesy.unr.edu/NGLStationPages/steps.txt (accessed on 17 February 2022). For the missing values, we used the regularized expectation-maximization (RegEM) [43] algorithm to interpolate the data and obtain the complete time series. We next applied an ICA regional filter to these complete time series and subsequently confirmed the ONM for all GPS time series based on the Akaike information criterion (AIC). Finally, we used the high-accuracy GPS velocity field to assess the performance of the 7 GIA models over Antarctica. The entire technical flow of this work is depicted in Figure 2.

\subsection{ICA Filtering}

As indicated in previous studies $[23,24]$, ICA is a blind-source signal separation method, and we needed to maximize the non-Gaussian distribution of the output. When ICA is applied to GPS time series, each row vector is the GPS coordinate series with the trend and mean terms removed. In this paper, we used the FastICA algorithm $[23,44]$ to estimate the independent components (ICs). A detailed description of the ICA filtering technique can be found in $[25,33]$.

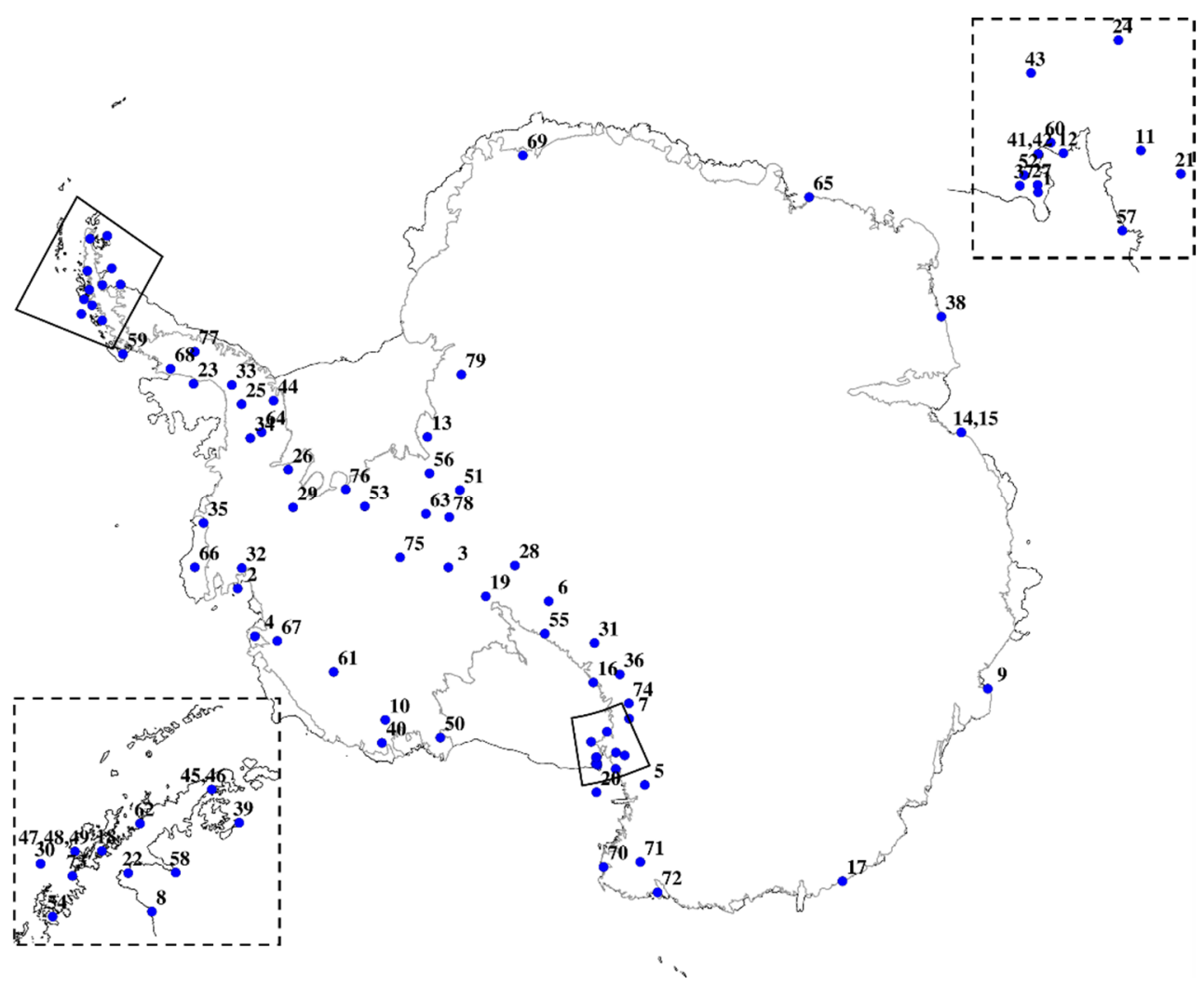

Figure 1. The distribution of the global positioning system (GPS) stations in Antarctica. 


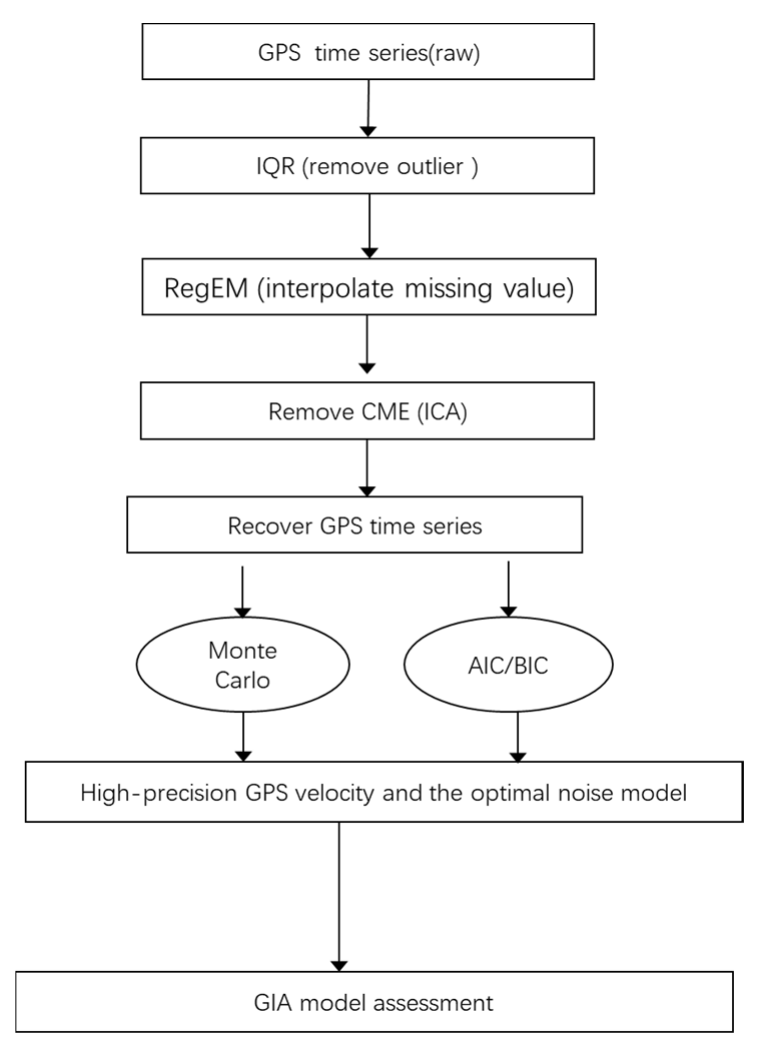

Figure 2. The technical flow of the data processing framework.

First, we performed a parallel analysis (PA) to confirm how many ICs are statistically significant [45]. To investigate the influence of colored noise, we compared the simulation results with and without colored noise. The colored noise was generated by Fakenet [46]. Figure S1 shows the PA test results of ICs with and without colored noise data, from which we can see that the first 7 eigenvalues are statistically significant and that colored noise has little influence. To avoid missing some information, we adopted the first 8 ICs for ICA filtering.

Figure 3 shows the spatial responses of IC1-IC8, from which we can conclude that IC2 has a uniform spatial coherence. In addition, while IC4 and IC8 are neither completely random nor completely identical, they exhibit obvious spatially uniform localized patterns or strong spatial coherence across the network. In addition, IC7 exhibits spatially uniform localized patterns in some areas, but the pattern is not entirely uniform, which we suppose is because unmodeled signals, local effects, and other factors are not considered herein. Based on these spatial responses, we used IC2, IC4, IC7, and IC8 to extract the CMEs.

Figure S2 shows the RegEM-interpolated coordinate time series (with the trends and annual and semiannual terms removed) and the raw time series of station GMEZ before and after implementing ICA filtering. The results clearly reveal that the scattering in the filtered time series is effectively reduced by the ICA filter, as the mean root mean square (RMS) decreases from 6.41 to $4.46 \mathrm{~mm}$; the maximum reduction in the RMS value is $48.41 \%$, the minimum is $10.83 \%$, and the mean reduction is $30.81 \%$.

Figure 4 shows the RMS values of the residual time series before and after applying the ICA filters, and the color bar reflects the RMS reduction percentage. Notably, the RMS values have larger reductions on the South Antarctic Peninsula (SAP) and the FilchnerRonne Ice Shelf (FRIS); furthermore, the reductions in the RMS values near the coast are smaller than those in the Antarctic interior. 

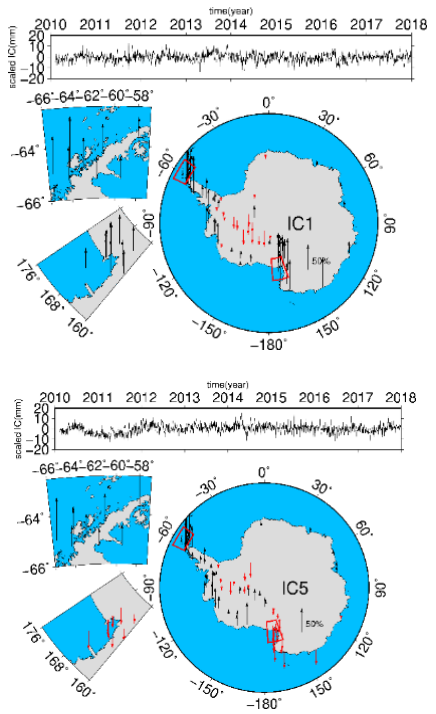
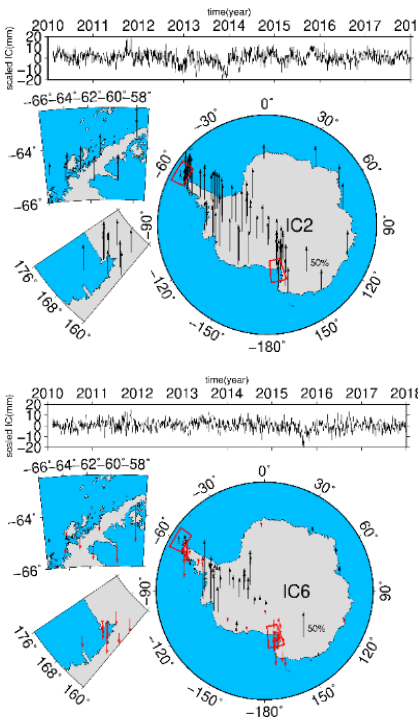
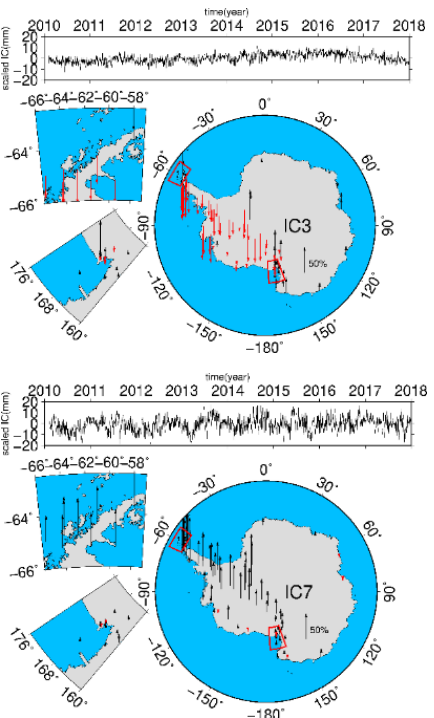
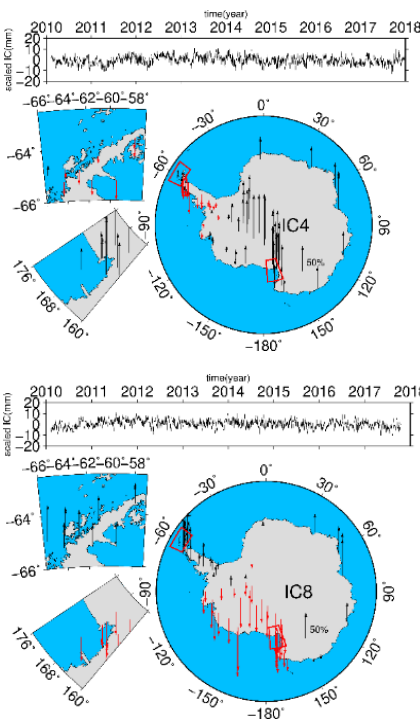

Figure 3. The results of IC1-IC8 (the black arrows signify a positive spatial response, and the red arrows signify a negative spatial response).

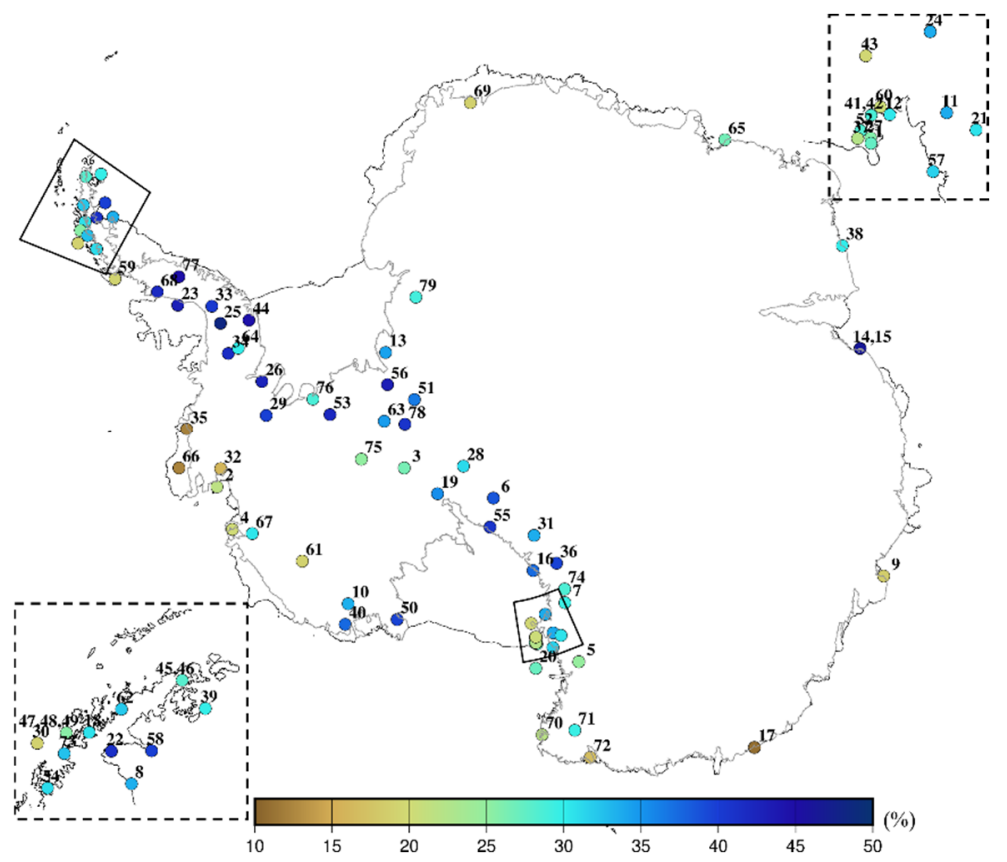

Figure 4. The RMS reduction percentage of the residual time series before and after applying the ICA filters (\%).

\subsection{AIC and Noise Analysis}

One of the most important factors in guaranteeing the accuracy GPS coordinate time series is the noise model. Unfortunately, the ONM varies considerably because of local effects among the stations in a network. Therefore, it is not possible to reasonably and effectively model all GPS station time series with only one noise model. In this study, we used the AIC [47] to confirm the quality of the selected noise models. The definition of the $\log$-likelihood $L$ is as follows:

$$
\ln (L)=-\frac{1}{2}\left[N \ln (2 \pi)+\ln \operatorname{det}(C)+r^{T} C^{-1} r\right]
$$


where $N$ is the actual number of GPS observations (not including gaps), and $r$ is the residual vector of the time series. The covariance matrix $C$ is decomposed as follows:

$$
C=\sigma 2 \bar{C}
$$

where $\bar{C}$ is the sum of various noise models, and $\sigma$ is the standard deviation of the driving $\mathrm{WN}$ process, where $\sigma$ is estimated from the residuals:

$$
\sigma=\sqrt{\frac{r^{T} \bar{C}^{-1} r}{N}}
$$

Then, the AIC can be defined as follows:

$$
A I C=2 k+2 \ln (L)
$$

Because $\operatorname{detc} A=c^{N} \operatorname{det} A$, the following formulation is implemented for the log-likelihood:

$$
\ln (L)=-\frac{1}{2}[N \ln (2 \pi)+\ln \operatorname{det}(\bar{C})+2 N \ln (\sigma)+N]
$$

where $k$ is the sum of the parameters in the design matrix and the noise models. The minimum AIC corresponds to the better model.

To determine the ONM for Antarctica, we evaluated 5 noise models supplied by Hector [42], namely, WN + PL, WN + RW, WN + FN, WN + FN + RW, and WN + RW + GGM, to analyze the 79 GPS station time series based on the AIC. The noise analysis results for the corresponding velocities listed in Table S1 show that the WN + FN ONM accounts for $22 \%$ (18 GPS stations), whereas the WN + RW + GGM model accounts for only 5.1\% (4 GPS stations), while the WN + PL model accounts for 72.2\% (57 GPS stations). Furthermore, we calculated the PL spectral index and discovered that most of the PL spectral index approximates the FN, which indicates that PL is essentially similar to FN in Antarctica.

\section{Results}

\subsection{GPS Velocity Field}

After implementing the AIC noise analysis and ICA filters, we obtained a highprecision GPS velocity field. Next, we compared the differences between this velocity field

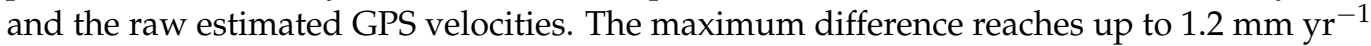
(WWAY), while the mean difference is $0.2 \mathrm{~mm} \mathrm{yr}^{-1}$, and the velocity differences at $21 \%$ (17) of the stations are greater than $\pm 0.4 \mathrm{~mm} \mathrm{yr}^{-1}$. We excluded nine stations with inappropriate percentage statistics (that is, whose processed GPS velocities are far greater than the raw velocities or whose velocity directions change after applying the AIC and performing ICA): FIE0, BUMS, MAW1, PECE, OHI2, STEW, VESL, MCM4, and HOOZ. Then, we calculated the percentage of velocities that vary relative to the raw GPS velocities at each station. The maximum proportion of processed velocities is $80.22 \%$ (ABBZ, at which the velocity is very small), and the mean variation is $11.39 \%$. We found that the maximum velocity variation is up to $0.9 \mathrm{~mm} \mathrm{yr}^{-1}$, and the mean variation is $0.6 \mathrm{~mm} \mathrm{yr}^{-1}$ at the remaining nine stations. Considering the magnitudes of the elastic and GIA loading signals, we cannot ignore these effects.

Figure 5 shows the GPS velocity field after applying the noise analysis and the AIC filter to Antarctica. The overall trend is upward, with station INMN exhibiting a maximum uplift velocity of $32.6 \mathrm{~mm} \mathrm{yr}^{-1}$, and the mean velocity among all Antarctic GPS stations is $3.3 \mathrm{~mm} \mathrm{yr}^{-1}$ (TOMO was removed because of some abnormal variations) [32]. Due to the reduced upper mantle viscosity and mass loss caused by the collapse of the Larsen-B Ice Shelf [31], the North Antarctic Peninsula (NAP) mean uplift velocities (5.8 $\mathrm{mm} \mathrm{yr}^{-1}$ ) are larger than those of the SAP $\left(3.7 \mathrm{~mm} \mathrm{yr}^{-1}\right)$. In addition, the FRIS mean uplift velocities $\left(4.7 \mathrm{~mm} \mathrm{yr}^{-1}\right.$ ) are larger than those of the Ross Ice Shelf (ROSS, $0.74 \mathrm{~mm} \mathrm{yr}^{-1}$ ). The

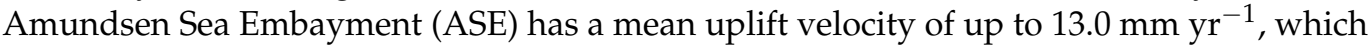


is the maximum amount of ice mass loss $[48,49]$. The most stable region is the coast of East Antarctica (EA), where the mean uplift velocity is only $0.1 \mathrm{~mm} \mathrm{yr}^{-1}$.

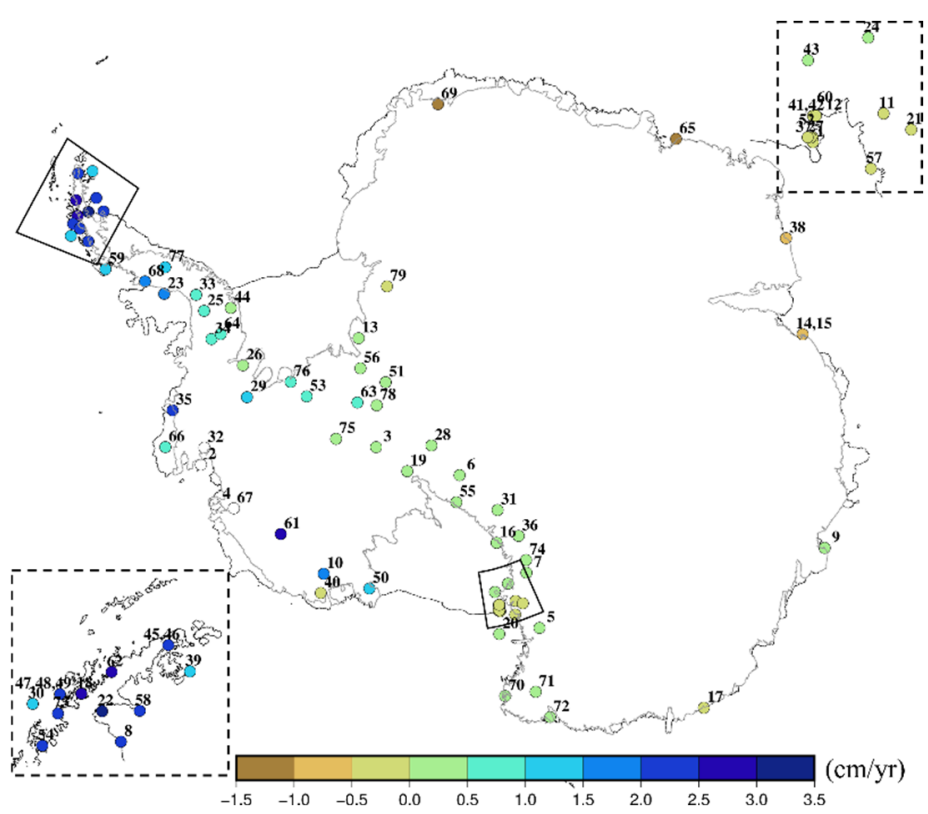

Figure 5. The GPS vertical velocity field after applying the noise analysis and AIC filter $\left(\mathrm{cm} \mathrm{yr}^{-1}\right)$.

The GPS data time span also has an important effect on the estimated velocities. For example, the velocity at station CAPF (8, Figure 1 ) has an estimated vertical velocity of $15 \pm 8.4 \mathrm{~mm} \mathrm{yr}^{-1}$ based on approximately two years of GPS data. This is larger than our estimated value of $4.1 \pm 0.3 \mathrm{~mm} \mathrm{yr}^{-1}$ [13]. In addition, at ROB4 located on the west coast of the ROSS, we estimated the vertical velocity to be $1.1 \pm 0.2 \mathrm{~mm} \mathrm{yr}^{-1}$, which is similar to the estimate of $2.2 \pm 3.2 \mathrm{~mm} \mathrm{yr}^{-1}$ in [13] based on approximately six years of GPS data but is dramatically different from that of $7.5 \pm 2.6 \mathrm{~mm} \mathrm{yr}^{-1}$ in [30] based on 558 days of GPS data. These differences show that the GPS data time span plays an important role in the estimation of velocities and that longer time spans correspond to more reliable velocity estimates.

\subsection{Ice Mass Elastic Loading}

In Antarctica, the GPS uplift velocities are dominated by elastic deformation due to the ongoing ice mass loading and GIA. In this study, we use a $10 \times 10 \mathrm{~km}$ grid of the monthly SECs of the Antarctic ice sheet from multiple satellite altimetry missions (Seasat, Geosat, ERS-1, ERS-2, Envisat, ICESat and CryoSat-2) provided by [50]. Following [51], SECs can be converted into mass change rates by multiplying the results by a density model of ice/snow lost or gained. Here, we calculated the density using the method proposed by [11]. We used Green's functions to calculate the elastic vertical displacements caused by ice mass loading (reference epoch: 2010.09) using the Preliminary Reference Earth Model (PREM) in Antarctica [52]. The results show that the ASE and AP regions have larger elastic loading velocities and mean magnitudes of 13.46 and $5.52 \mathrm{~mm} \mathrm{yr}^{-1}$, respectively, whereas the FRIS and ROSS regions have smaller elastic velocities, and most of the GPS signals in EA feature a negative elastic response. In some areas, the estimated GIA uplift rates are significantly contaminated by neglecting the elastic responses of various geophysical phenomena.

\subsection{GIA Assessment}

To explore the application of GIA models in different regions, we divided Antarctica into six subregions [32,53]. The station information is indexed in Table S1. Figure 6 shows the predicted uplift velocities using the seven GIA models. The maximum, minimum, mean, and RMS values of the uplift velocities are listed in Table 1. These GIA models 
predict uplift maxima over the FRIS and ROSS regions and the AP. The SAP, ASE, ROSS, and FRIS have larger uplift velocities, which may be attributable to these regions losing the most ice mass since last glacial maximum and to the rapid response of the solid Earth [32]. The vertical velocities predicted over WA are larger than those in the basins in EA, while the vertical velocities have smaller values along coastal EA, and the subsidence areas in the interior vary across the different solutions, which may be because of the reduced upper mantle viscosity and higher velocities in EA [54,55]. Because of the lack of data chronicling the history of ice gain/loss in these GIA models, the solutions vary slightly in EA [32]. Nevertheless, the spatial variability among all the GIA models is larger than the GIA signal itself in many cases, especially in the interior of EA where the mean GIA velocities are small. We ultimately found that the western margin of the ROSS, the ASE, the FRIS, and the AP have maximum variability.

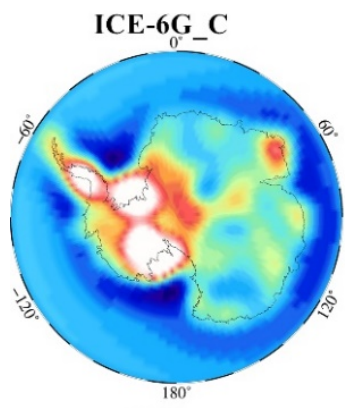

W12a

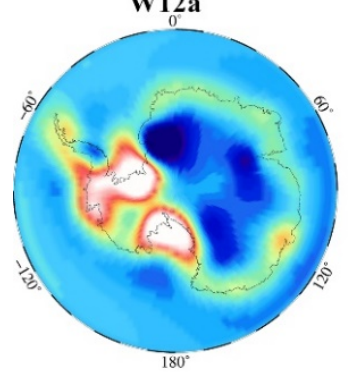

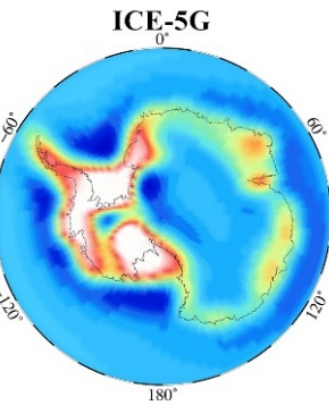

Geruo13

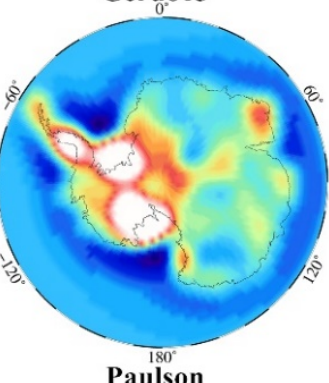

Paulson

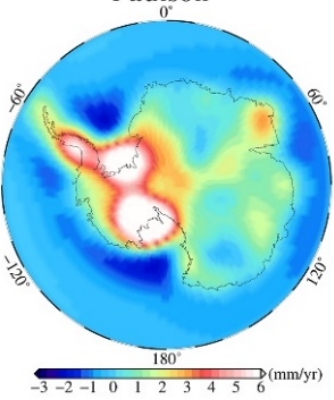

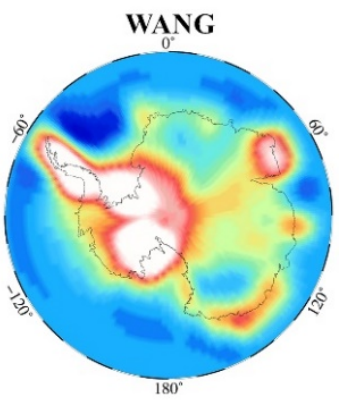

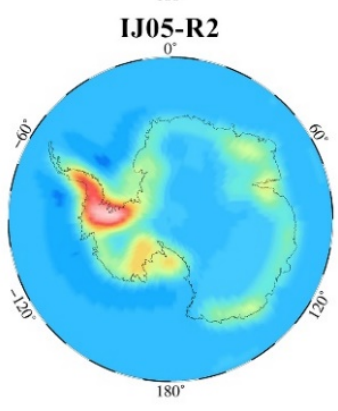

Figure 6. Predicted uplift velocities using the 7 GIA models.

Table 1. The maximum, minimum, and mean values and standard deviations of the 7 glacial isostatic adjustment (GIA) model uplift velocities $\left(>60^{\circ} \mathrm{S}\right)$.

\begin{tabular}{|c|c|c|c|c|}
\hline GIA & $\operatorname{Max}\left(\mathrm{mm} \mathrm{yr}^{-1}\right)$ & $\operatorname{Min}\left(\mathrm{mm} \mathrm{yr}^{-1}\right)$ & Mean $\left(\mathrm{mm} \mathrm{yr}^{-1}\right)$ & Std $\left(\mathrm{mm} \mathrm{yr}^{-1}\right)$ \\
\hline ICE-6G & 13.50 & -2.20 & 0.71 & 1.15 \\
\hline ICE-5G & 13.90 & -2.80 & 1.58 & 1.10 \\
\hline WANG & 15.27 & -2.13 & 2.60 & 1.15 \\
\hline W12a & 10.33 & -6.11 & 0.58 & 0.97 \\
\hline Geruo13 & 15.00 & -2.70 & 1.34 & 1.19 \\
\hline IJ05-R2 & 5.24 & -0.88 & 0.22 & 0.45 \\
\hline Paulson & 12.46 & -1.98 & 1.50 & 1.07 \\
\hline
\end{tabular}


Generally, these Antarctic GIA models still have great uncertainties due to a lack of adequately accurate data as constraints. Following [32], we used the weighted mean (WM), weighted root mean square (WRMS) and median to evaluate the consistency between the GPS vertical velocities and GIA model velocities. The WM and WRMS are defined by Formulas (6) and (7):

$$
\begin{aligned}
\mathrm{WM} & =\frac{\sum_{i=1}^{79}\left(p_{i}-O_{i}\right) w_{i}}{\sum_{i=1}^{79} w_{i}} \\
\mathrm{WRMS} & =\sqrt{\frac{\sum_{i=1}^{79}\left(P_{i}-O_{i}\right)^{2} w_{i}}{\sum_{i=1}^{79} w_{i}}}
\end{aligned}
$$

where $P_{i}$ and $O_{i}$ are the GIA-modeled and GPS-observed velocities, respectively, and $W_{i}$ is the weight factor obtained by the GPS measurement errors at each station:

$$
w_{i}=\frac{1}{c_{i}\left(\sigma_{i} G P S\right)^{2}} i=1, \cdots 79
$$

where $\sigma_{i}$ represents the error at the GPS station, and $c_{i}$ is calculated as follows:

$$
C_{i}=\sum_{j=1}^{79} \exp \left(\frac{-d_{i j}}{I}\right)
$$

where $x$ is the distance matrix and $d_{i j}$ is the (ith, jth) value of $x$ relative to the 79 GPS locations. To deweight the sites near other sites, we used the scale parameter I. Similar to [32], we assumed $I=250 \mathrm{~km}$. We first removed the elastic deformation from the GPS time series (it is assumed that the elastic model is accurate), and then applied the ICA method for the elastic-corrected residual time series to remove CME. Finally, we used AIC to determine the noise model. The results are listed in Tables 2 and 3.

Table 2. The weighted mean (WM) residuals for the North Antarctic Peninsula (NAP), South Antarctic Peninsula (SAP), Amundsen Sea Embayment (ASE), Margins of the Ross Ice Shelf (ROSS) and Filcher-

\begin{tabular}{|c|c|c|c|c|c|c|c|c|}
\hline \multicolumn{2}{|c|}{ Regions/GIA } & \multirow{2}{*}{$\begin{array}{c}\text { ICE6G } \\
0.83\end{array}$} & \multirow{2}{*}{$\begin{array}{c}\text { ICE5G } \\
-0.99\end{array}$} & \multirow{2}{*}{$\begin{array}{c}\text { WANG } \\
2.30\end{array}$} & \multirow{2}{*}{$\begin{array}{c}\text { W12a } \\
0.86\end{array}$} & \multirow{2}{*}{$\begin{array}{c}\text { Geruo13 } \\
-0.94\end{array}$} & \multirow{2}{*}{$\begin{array}{c}\text { IJ05R2 } \\
-1.03\end{array}$} & \multirow{2}{*}{$\begin{array}{c}\text { Paulson } \\
0.88\end{array}$} \\
\hline & $\mathrm{a}$ & & & & & & & \\
\hline Antarctica & $\mathrm{b}$ & 0.78 & -1.04 & 2.25 & 0.86 & -0.99 & -1.08 & 0.93 \\
\hline & c & -0.48 & -0.69 & 2.10 & -0.45 & -0.75 & -0.84 & 0.63 \\
\hline \multirow{3}{*}{ ROSS } & $\mathrm{a}$ & 1.24 & 1.46 & 2.26 & 2.81 & 1.43 & -0.74 & 1.24 \\
\hline & $\mathrm{b}$ & 1.18 & 1.40 & 2.21 & 2.87 & 1.37 & -0.80 & 1.18 \\
\hline & c & 0.98 & 1.20 & 2.00 & 2.60 & 1.17 & -1.00 & 0.98 \\
\hline \multirow{3}{*}{ NAP } & $\mathrm{a}$ & -4.58 & -7.96 & -1.32 & -5.31 & -7.68 & -7.04 & -5.39 \\
\hline & $\mathrm{b}$ & -4.94 & -8.31 & -1.67 & -5.37 & -8.03 & -7.39 & -5.75 \\
\hline & c & -0.78 & -4.15 & 2.49 & -3.51 & -6.87 & -3.23 & -1.59 \\
\hline \multirow{3}{*}{ SAP } & $\mathrm{a}$ & 2.50 & -1.73 & 4.24 & -2.53 & -1.65 & 0.33 & 1.83 \\
\hline & $\mathrm{b}$ & 2.30 & -1.92 & 4.05 & -2.72 & -1.85 & 0.13 & 1.64 \\
\hline & c & 1.62 & -2.60 & 3.37 & -3.40 & -2.53 & -0.55 & 0.96 \\
\hline \multirow{3}{*}{ ASE } & $\mathrm{a}$ & -0.99 & -6.69 & -5.13 & -2.56 & -6.61 & -5.98 & -6.56 \\
\hline & $\mathrm{b}$ & -0.70 & -6.10 & -4.54 & -1.97 & -6.02 & -5.39 & -5.97 \\
\hline & c & -0.40 & -5.11 & -3.54 & -6.98 & -5.03 & -4.39 & -3.97 \\
\hline \multirow{3}{*}{ EA } & $\mathrm{a}$ & 0.69 & -0.49 & 2.10 & 1.05 & -0.51 & 0.27 & 0.53 \\
\hline & $b$ & 0.66 & -0.52 & 2.06 & 1.05 & -0.55 & 0.24 & 0.50 \\
\hline & c & 0.44 & -0.74 & 1.84 & 0.80 & -0.77 & 0.02 & 0.28 \\
\hline
\end{tabular}
Ronne Ice Shelf (FRIS), and East Antarctica (EA) (a is the raw GPS with elastic correction corrected, $\mathrm{b}$ is conducted by ICA with elastic correction corrected, $\mathrm{c}$ is conducted by ICA and AIC with elastic correction corrected). 
Table 2. Cont.

\begin{tabular}{ccccccccc}
\hline \multicolumn{2}{c}{ Regions/GIA } & ICE6G & ICE5G & WANG & W12a & Geruo13 & IJ05R2 & Paulson \\
\hline \multirow{2}{*}{ FRIS } & $\mathrm{a}$ & 2.32 & -2.24 & 3.00 & 2.38 & -2.17 & 0.66 & 1.61 \\
& $\mathrm{~b}$ & 2.52 & -2.04 & 3.20 & 2.58 & -1.97 & 0.87 & 1.82 \\
& $\mathrm{c}$ & 1.20 & -3.36 & 1.88 & 1.26 & -3.29 & -0.45 & 0.50 \\
\hline
\end{tabular}

Table 3. The weighted root mean square (WRMS) residuals in the North Antarctic Peninsula (NAP), South Antarctic Peninsula (SAP), Amundsen Sea Embayment (ASE), Margins of the Ross Ice Shelf (ROSS) and Filcher-Ronne Ice Shelf (FRIS), and East Antarctica (EA) (a is the raw GPS with elastic correction corrected, $\mathrm{b}$ is conducted by ICA with elastic correction corrected, $\mathrm{c}$ is conducted by ICA and AIC with elastic correction corrected).

\begin{tabular}{|c|c|c|c|c|c|c|c|c|}
\hline Regions/GIA & & ICE6G & ICE5G & WANG & W12a & Geruo13 & IJ05R2 & Paulson \\
\hline \multirow{3}{*}{ Antarctica } & $\mathrm{a}$ & 4.00 & 5.68 & 4.27 & 4.90 & 5.57 & 5.14 & 4.68 \\
\hline & $\mathrm{b}$ & 4.03 & 5.99 & 4.45 & 5.14 & 5.88 & 5.40 & 4.94 \\
\hline & c & 3.73 & 3.93 & 4.05 & 3.72 & 3.84 & 3.45 & 3.37 \\
\hline \multirow{3}{*}{ ROSS } & $\mathrm{a}$ & 1.58 & 2.16 & 2.93 & 3.41 & 2.11 & 1.50 & 1.88 \\
\hline & $\mathrm{b}$ & 1.59 & 2.14 & 2.96 & 3.33 & 2.09 & 1.54 & 1.94 \\
\hline & $\mathrm{c}$ & 1.51 & 2.12 & 2.84 & 3.19 & 2.08 & 1.76 & 1.88 \\
\hline \multirow{3}{*}{ NAP } & $\mathrm{a}$ & 6.56 & 9.65 & 4.55 & 7.28 & 9.40 & 8.64 & 7.33 \\
\hline & $\mathrm{b}$ & 6.89 & 9.99 & 4.78 & 7.60 & 9.74 & 8.98 & 7.65 \\
\hline & c & 3.82 & 6.01 & 4.35 & 4.21 & 5.79 & 5.13 & 4.25 \\
\hline \multirow{3}{*}{ SAP } & $\mathrm{a}$ & 3.15 & 3.43 & 5.60 & 4.08 & 3.38 & 2.56 & 3.62 \\
\hline & $\mathrm{b}$ & 2.96 & 3.44 & 5.36 & 4.17 & 3.39 & 2.42 & 3.41 \\
\hline & c & 3.22 & 3.41 & 4.20 & 4.47 & 3.35 & 1.75 & 2.32 \\
\hline \multirow{3}{*}{ ASE } & $\mathrm{a}$ & 5.67 & 8.78 & 7.65 & 6.09 & 8.72 & 8.34 & 8.60 \\
\hline & $\mathrm{b}$ & 5.69 & 8.41 & 7.34 & 5.95 & 8.34 & 8.00 & 8.23 \\
\hline & c & 5.72 & 5.76 & 7.75 & 5.25 & 8.70 & 8.42 & 8.57 \\
\hline \multirow{3}{*}{ EA } & $\mathrm{a}$ & 1.43 & 1.87 & 2.74 & 1.77 & 1.83 & 1.67 & 1.79 \\
\hline & $b$ & 1.46 & 1.87 & 2.76 & 1.76 & 1.84 & 1.64 & 1.79 \\
\hline & c & 2.27 & 3.19 & 3.03 & 2.77 & 3.11 & 3.10 & 2.87 \\
\hline \multirow{3}{*}{ FRIS } & $\mathrm{a}$ & 2.53 & 3.10 & 4.91 & 2.95 & 3.04 & 2.33 & 3.01 \\
\hline & $b$ & 2.72 & 2.94 & 5.00 & 3.12 & 2.89 & 2.41 & 3.09 \\
\hline & c & 1.63 & 3.82 & 4.50 & 2.18 & 3.75 & 1.60 & 2.72 \\
\hline
\end{tabular}

Table 2 shows the WMs for all of Antarctica and the subregions. From Table 2, we can see that all GIA-predicted velocities have significant differences with GPS-observed velocity (a). After applying the ICA filter (b), the difference is changed slightly; for most GIA models, the difference is reduced, maybe because the original system deviation becomes smaller after ICA filtering. With further applied noise models (c), almost all differences are reduced significantly, which means that the consistency between GIA-predicted velocity and GPS-observed velocity has been further improved. We can also conclude that the change of GPS velocity is mainly due to the application of noise models.

Table 3 shows the WRMSs for all of Antarctica and the subregions. The WRMSs for most of GIA models are reduced, which means that the raw GPS velocities are affected by local effects or errors and which is depressed after applying the ICA filter and noise analysis.

Figure 7 shows the summary statistics of the WM and WRMS and the median values of the residuals (GPS velocities after applying the ICA filter and the ONM- and GIA modelpredicted velocities). The WM of the GPS velocities and WANG model is $1.39 \mathrm{~mm} \mathrm{yr}^{-1}$, which indicates that the velocities predicted by WANG are systematically larger than the GPS-observed velocities. The WMs of the other 6 GIA models range from -0.09 to $-2.0 \mathrm{~mm} \mathrm{yr}^{-1}$, which means that the GIA model-predicted velocities are systematically smaller than the GPS-observed velocities. WANG has the maximum median and WM 
values, while those of ICE-6G and W12a are relatively small, which indicates that these two models are unbiased with respect to the GPS velocities. ICE-6G has the minimum WRMS, which we infer to be because ICE-6G employs GPS data as a constraint [13].
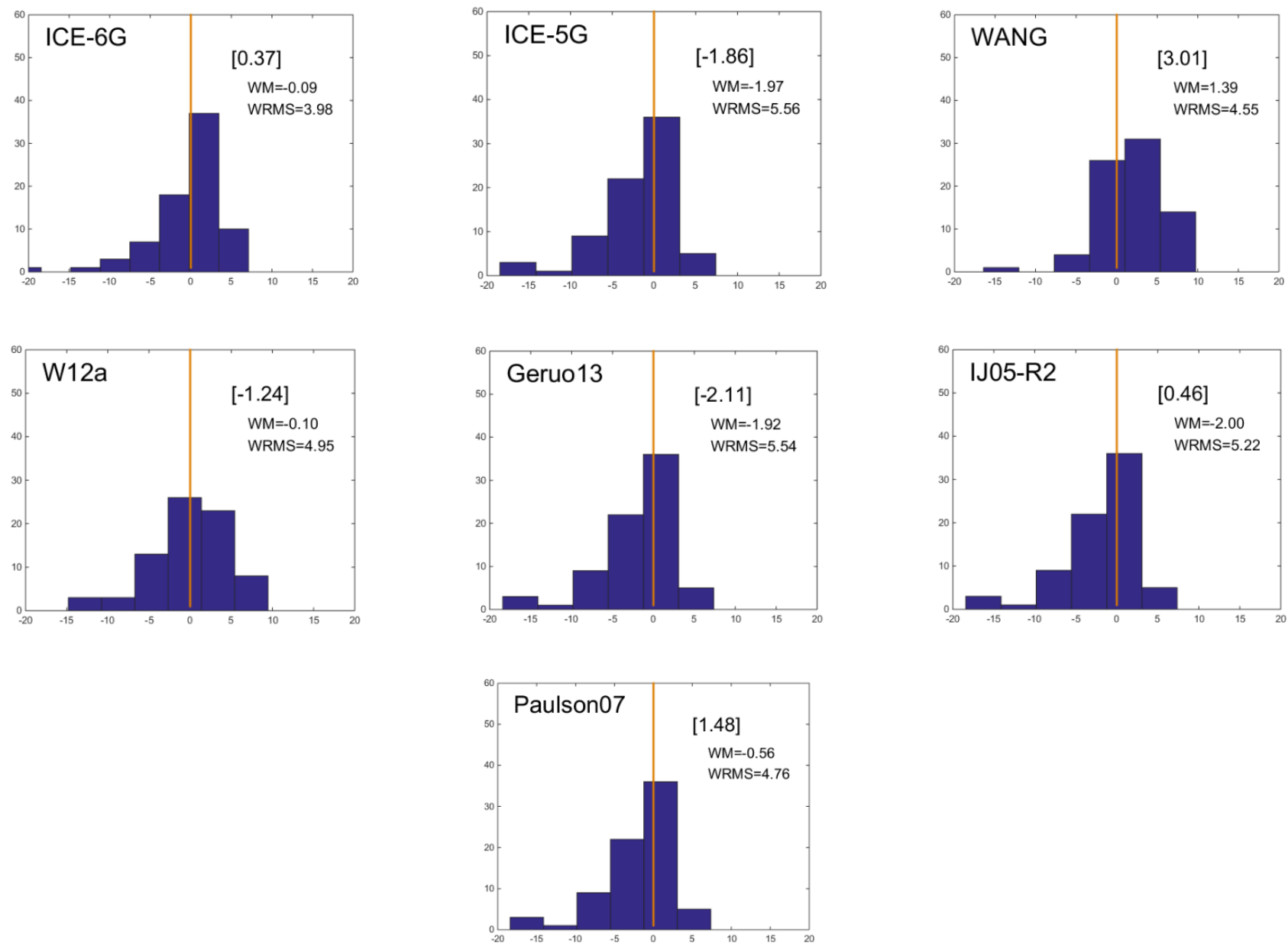

Figure 7. The summary statistics of the WM and WRMS; median values are indicated in parentheses $\left(\mathrm{mm} \mathrm{yr}^{-1}\right)$.

\section{Discussion}

To evaluate the applicability of the GIA models in Antarctica, the estimated velocities and observed vertical velocities from an independent set of 79 GPS stations were compared. Figure 8 shows the discrepancies between the GIA velocities and GPS uplift rates at each GPS site. Next, we performed a regional analysis and interpret the GIA uplift rates.

Amundsen Sea Embayment (ASE): The ASE is undergoing considerable ice mass loss, and the contributions from GIA and the upper mantle have significant effects on the gravity-derived ice mass variation estimates and ice sheet stability, respectively. Comparing the differences between the GIA models and GPS velocity results (after elastic corrections) reveals that important differences still remain in West Antarctica, especially for the ASE and North Antarctic Peninsula. Figure 8 shows the differences between the GPS and GIA velocities at each GPS site, indicating that the worst match occurs in the ASE. ICE-6G has a maximum uplift velocity of approximately $7 \mathrm{~mm} \mathrm{yr}^{-1}$, has an intermediate upper mantle value among the GIA models and predicts the largest present-day uplift velocity in the ASE [49], followed by W12a, which has an uplift velocity of approximately $5 \mathrm{~mm} \mathrm{yr}^{-1}$, whereas the other models predict uplift velocities within $2 \mathrm{~mm} \mathrm{yr}^{-1}$. Zhang et al. (2017) revealed that the ASE region has experienced the most significant ice mass loss and most significant elastic vertical crustal deformation in Antarctica [51]. 


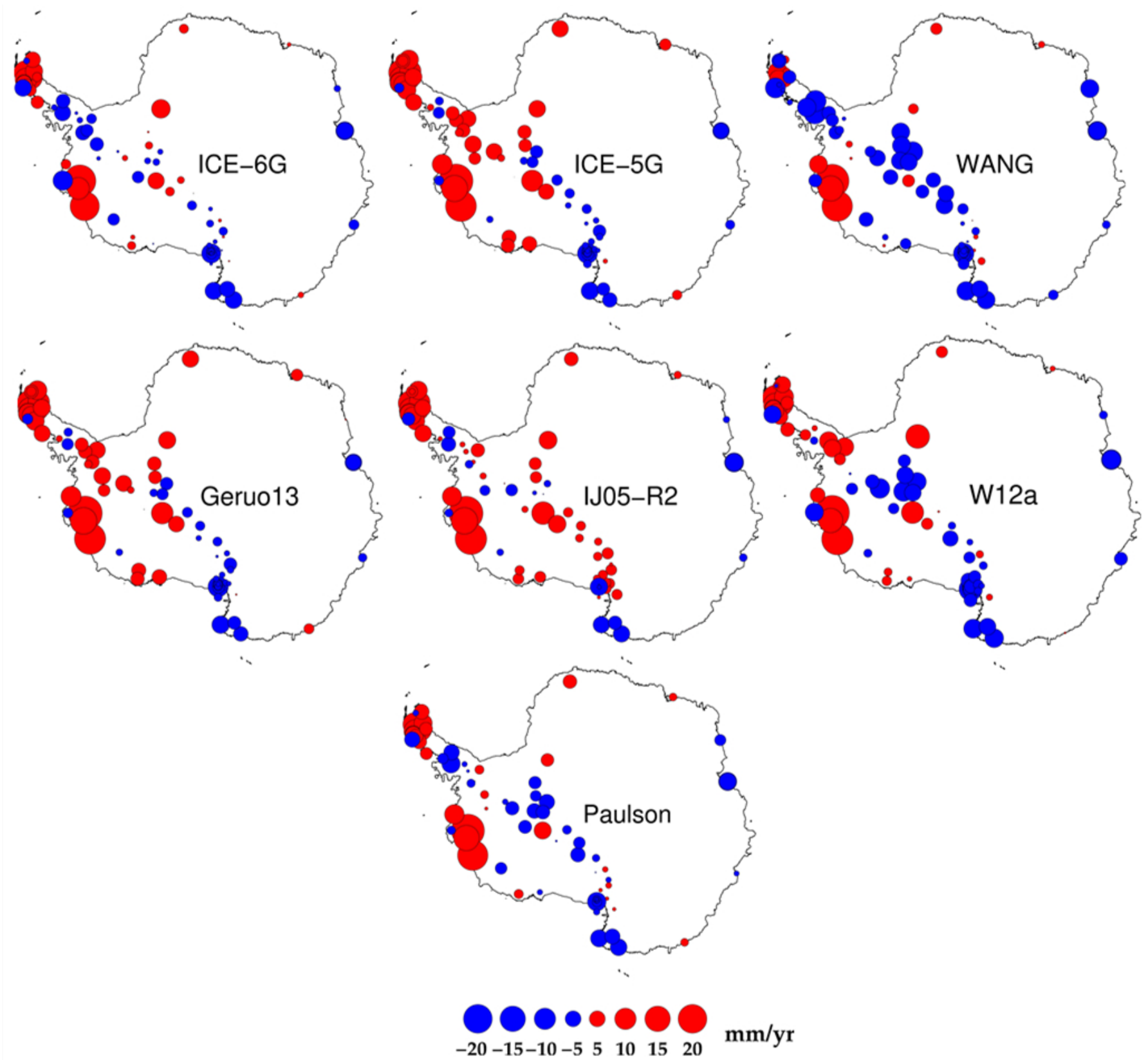

Figure 8. The discrepancies between the modeled and observed GIA uplift rates estimated from different solutions computed at each GPS site (red circles indicate places where the estimated GIA rates underestimate the GPS-observed velocities; blue circles indicate overestimations).

Ross Ice Shelf (ROSS): The GIA models slightly overestimate GIA velocities on the ROSS. King et al. (2012) showed that the GIA signal on the ROSS should be close to zero by examining GRACE data [56]. The GRACE signal should be dominated by GIA signals and small ocean mass changes. Nield et al. (2016) predicted that the uplift velocity across the Siple Coast is more than $4 \mathrm{yr} \mathrm{mm}^{-1}$ and reported small GIA vertical velocities over the ROSS and Siple Coast only when the upper mantle viscosity was $0.5-1.0 \times 10^{20} \mathrm{~Pa} \cdot \mathrm{s}$ [57], which is compatible with the findings of King et al. (2012), who also showed that Late Holocene ice loading changes may have a dominant influence on the ongoing uplift of this region. In our study, the GPS velocities on the ROSS ranged from -2.3 to $7.0 \mathrm{~mm} \mathrm{yr}^{-1}$, and the mean velocity is approximately $0.7 \mathrm{~mm} \mathrm{yr}^{-1}$.

Antarctic Peninsula (AP): The GPS vertical velocities in the AP are generally larger than the predictions of all GIA models. This study's uplift estimate at station FONP is 
$11.9 \mathrm{~mm} \mathrm{yr}^{-1}$, while the mean GIA prediction is $2.0 \mathrm{~mm} \mathrm{yr}^{-1}$. One possible cause for such a difference is the crustal elastic response to modern ice mass changes. The Prince Gustav Ice Shelf and Larsen-A Ice Shelf collapsed in 1995. In addition, the neighboring Larsen-B Ice Shelf, which partially collapsed in 2002, is quickly weakening and is likely to completely disintegrate before the end of the decade. This is particularly relevant because ice shelves regulate the flow of glaciers from Antarctica toward the ocean [32]. The GPS vertical velocities on the North Antarctic Peninsula are generally larger than those on the South Antarctic Peninsula, which is in agreement with the findings of [58], indicating a moderately low upper mantle viscosity beneath the South Antarctic Peninsula, although it is not as low as that beneath the North Antarctic Peninsula. Nield et al. (2014) found the upper mantle viscosities of between $6 \times 10^{17}$ and $2 \times 10^{18} \mathrm{~Pa} \cdot \mathrm{s}$ beneath the North Antarctic Peninsula [31] (same as [59]); their results show that the lithospheric thickness and upper mantle viscosity are much lower than those in previous studies.

Filchner-Ronne Ice Shelf (FRIS): The FRIS is near the Weddell Sea Embayment; the crustal and lithospheric thickness transitions between East Antarctica and West Antarctica

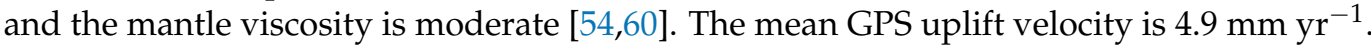
The GPS and GIA model results agree overall; thus, we postulated that the uplift in this ice shelf is mainly caused by the GIA in this region, which agrees with the findings of [13,32].

East Antarctica (EA): The GPS vertical velocities along the coast of EA range from approximately -4.9 to $3.6 \mathrm{~mm} \mathrm{yr}^{-1}$ and are smaller than those in West Antarctica. The GIA model velocities agree with the GPS velocities, but the uplift velocities are underestimated by most GIA models from 0.33 to $1.71 \mathrm{~mm} \mathrm{yr}^{-1}$. The basement of EA is an ancient craton, and the geological structure is stable; thus, no significant geological activity occurs in this region. The vertical movements along the coast of EA are all nonsignificant, showing that the effects of GIA or recent ice and snow accumulations are small. GRACE gravity data from 2009-2013 show that the coast of Queen Maud Land in EA accumulated ice and snow at a rate of $150 \mathrm{Gt} \mathrm{yr}^{-1}$ [13]. Precipitation data from 2009-2012 also reflect rapid accumulation, but the accumulation during 1980-2008 was approximately zero, indicating that the recent accumulation of ice and snow is anomalous and represents interannual variations [61]. Overall, there is no significant geological activity in EA, and the effects of GIA and ice mass loading are small in this region.

\section{Conclusions}

High-precision global positioning system (GPS) data are effective for studying regional crustal displacements, the regional crustal displacements in Antarctica have important value as a reference for understanding the evolution of global plate tectonics as well as for creating and maintaining reference frames and monitoring the dynamics of ice and snow in polar regions. For the subregions of Antarctica with complex terrain, we removed the common mode errors (CMEs) of the residual GPS time series by applying independent component analysis (ICA) filters to the time series recorded at 79 GPS stations across Antarctica; then, the Akaike information criterion (AIC) was used to determine the optimal noise model (ONM). Finally, we used high-precision GPS data to assess the seven glacial isostatic adjustment (GIA) models. The results are as follows:

1. After applying an AIC noise analysis and ICA filtering, the maximum GPS velocity difference is up to $4.0 \mathrm{~mm} \mathrm{yr}^{-1}$, the mean difference is $0.4 \mathrm{~mm} \mathrm{yr}^{-1}$, and the velocity differences at $30 \%$ (24) of the stations are greater than $\pm 0.4 \mathrm{~mm} \mathrm{yr}^{-1}$.

2. After applying ICA filtering and noise analysis, the weighted means of the residuals between most of the GIA model-predicted and GPS-observed uplift velocities decrease in most regions. On the Filchner-Ronne Ice Shelf, the GPS-observed velocities and the GIA model-predicted velocities are consistent. In East Antarctica, vertical motions are nonsignificant, and GIA and ice loading have small impacts on this area.

3. For all 79 stations, the weight root mean squares are reduced, which means that the raw GPS velocities are affected by local effects. After applying the ICA filter and noise analysis, the local effects are depressed, and in the regions with relatively good 
consistency between the GPS-observed velocities and GIA model-predicted velocities, the consistency improves.

\begin{abstract}
Supplementary Materials: The following supporting information can be downloaded at: https: / / www.mdpi.com/article/10.3390/rs14051070/s1, Figure S1: The PA test results of the ICs (the left panel shows the results without colored noise, and the right panel shows the results with colored noise; the blue line is the GPS data, and the black and red lines are the maximum and minimum values of the simulation results, respectively); Figure S2: The residual time series (left) and raw time series (right) at station GMEZ before and after regional filtering by performing ICA (the blue lines are the raw time series, and the orange lines are the filtered time series); Table S1: GIA models information.
\end{abstract}

Author Contributions: Conceptualization, W.L. and C.K.S.; methodology, S.Z.; software, F.M., validation, Q.Z.; formal analysis, C.S.; investigation, W.C.; resources, W.L.; data curation, W.L.; writing-original draft preparation, W.L.; writing—review and editing, C.K.S.; visualization, C.K.S.; supervision, C.K.S.; project administration, F.L.; funding acquisition, F.L. All authors have read and agreed to the published version of the manuscript.

Funding: This research was funded by the National Key Research and Development Program of China (2017YFA0603104, 2017YFA0603103), the State Key Program of the National Natural Science Foundation of China (41531069), the National Natural Science Foundation of China (42074006, 41974040), the State Key Laboratory of Geo-Information Engineering and Key Laboratory of Surveying and Mapping Science and Geospatial Information Technology of the Ministry of Natural Resources (MNR), CASM (no. 2021-00-05), and the Project of Hydraulic Science and Technology of Jiangsu Province (no. 2018005, no. 2019001, no. 2020007, no. 2021063, and no. 2021074).

Data Availability Statement: The GPS time series were downloaded from: http://geodesy.unr. edu/NGLStationPages/GlobalStationList (accessed on 5 February 2022); the SECs data: http:/ /hs. pangaea.de/model/SchroderL-etal_2019/sec_mrg.nc (accessed on 5 February 2022).

Conflicts of Interest: The authors declare no conflict of interest.

\title{
References
}

1. Wang, H.S.; Wu, P.; van der Wal, W. Using postglacial sea level, crustal velocities and gravity-rate-of-change to constrain the influence of thermal effects on mantle lateral heterogeneities. J. Geodyn. 2008, 46, 104-117. [CrossRef]

2. Ivins, E.R.; James, T.S.; Wahr, J.; Schrama, E.J.O.; Landerer, F.W.; Simon, K.M. Antarctic contribution to sea level rise observed by GRACE with improved GIA correction. J. Geophys. Res. Solid Earth 2013, 118, 3126-3141. [CrossRef]

3. Argus, D.F.; Blewitt, G.; Peltier, W.R.; Kreemer, C. Rise of the Ellsworth mountains and parts of the East Antarctic coast observed with GPS. Geophys. Res. Lett. 2011, 38. [CrossRef]

4. Ke, H.; Li, F.; Zhang, S.K.; Ma, C.; Wang, A.X. The determination of absolute sea level changes of the Antarctic coast tidal gauges from 1994 to 2014 and its analysis. Chin. J. Geophys. 2016, 59, 3202-3210. [CrossRef]

5. Peltier, W.R. Global glacial isostasy and the surface of the ice-age earth: The ice-5G (VM2) model and grace. Annu. Rev. Earth Planet. Sci. 2004, 32, 111-149. [CrossRef]

6. Whitehouse, P.L.; Gomez, N.; King, M.A.; Wiens, D.A. Solid Earth change and the evolution of the Antarctic Ice Sheet. Nat. Commun. 2019, 10, 503. [CrossRef]

7. Jia, L.L.; Wang, H.S.; Xiang, L.W.; Wu, P.; Li, F.; Shi, H.L. Effects of glacial isostatic adjustment on the estimate of ice mass balance over Antarctica and the uncertainties. Chin. J. Geophys. 2011, 54, 1466-1477. [CrossRef]

8. Velicogna, I.; Wahr, J. Acceleration of Greenland ice mass loss in spring 2004. Nature 2006, 443, 329-331. [CrossRef]

9. Sasgen, I.; Martinec, Z.; Fleming, K. Regional ice-mass changes and glacial-isostatic adjustment in Antarctica from GRACE. Earth Planet. Sci. Lett. 2007, 264, 391-401. [CrossRef]

10. Riva, R.E.M.; Gunter, B.C.; Urban, T.J.; Vermeersen, B.L.A.; Lindenbergh, R.C.; Helsen, M.M.; Bamber, J.L.; de Wal, R.S.W.V.; van den Broeke, M.R.; Schutz, B.E. Glacial Isostatic Adjustment over Antarctica from combined ICESat and GRACE satellite data. Earth Planet. Sci. Lett. 2009, 288, 516-523. [CrossRef]

11. Gunter, B.C.; Didova, O.; Riva, R.E.M.; Ligtenberg, S.R.M.; Lenaerts, J.T.M.; King, M.A.; van den Broeke, M.R.; Urban, T. Empirical estimation of present-day Antarctic glacial isostatic adjustment and ice mass change. Cryosphere 2014, 8, 743-760. [CrossRef]

12. King, M.A.; Altamimi, Z.; Boehm, J.; Bos, M.; Dach, R.; Elosegui, P.; Fund, F.; Hernandez-Pajares, M.; Lavallee, D.; Cerveira, P.J.M.; et al. Improved Constraints on Models of Glacial Isostatic Adjustment: A Review of the Contribution of Ground-Based Geodetic Observations. Surv. Geophys. 2010, 31, 465-507. [CrossRef]

13. Argus, D.F.; Peltier, W.R.; Drummond, R.; Moore, A.W. The Antarctica component of postglacial rebound model ICE-6G_C (VM5a) based on GPS positioning, exposure age dating of ice thicknesses, and relative sea level histories. Geophys. J. Int. 2014, 198, 537-563. [CrossRef] 
14. Peltier, W.R.; Argus, D.F.; Drummond, R. Space geodesy constrains ice age terminal deglaciation: The global ICE-6G_C (VM5a) model. J. Geophys. Res. Solid Earth 2015, 120, 450-487. [CrossRef]

15. Wu, X.P.; Heflin, M.B.; Schotman, H.; Vermeersen, B.L.A.; Dong, D.A.; Gross, R.S.; Ivins, E.R.; Moore, A.; Owen, S.E. Simultaneous estimation of global present-day water transport and glacial isostatic adjustment. Nat. Geosci. 2010, 3, 642-646. [CrossRef]

16. Dong, D.; Fang, P.; Bock, Y.; Webb, F.; Prawirodirdjo, L.; Kedar, S.; Jamason, P. Spatiotemporal filtering using principal component analysis and Karhunen-Loeve expansion approaches for regional GPS network analysis. J. Geophys. Res. Solid Earth 2006, 111, B03405. [CrossRef]

17. Wdowinski, S.; Bock, Y.; Zhang, J.; Fang, P.; Genrich, J. Southern California Permanent GPS Geodetic Array: Spatial filtering of daily positions for estimating coseismic and postseismic displacements induced by the 1992 Landers earthquake. J. Geophys. Res. Solid Earth 1997, 102, 18057-18070. [CrossRef]

18. Serpelloni, E.; Faccenna, C.; Spada, G.; Dong, D.A.; Williams, S.D.P. Vertical GPS ground motion rates in the Euro-Mediterranean region: New evidence of velocity gradients at different spatial scales along the Nubia-Eurasia plate boundary. J. Geophys. Res. Solid Earth 2013, 118, 6003-6024. [CrossRef]

19. Shen, Y.Z.; Li, W.W.; Xu, G.C.; Li, B.F. Spatiotemporal filtering of regional GNSS network's position time series with missing data using principle component analysis. J. Geod. 2014, 88, 1-12. [CrossRef]

20. He, X.X.; Hua, X.H.; Yu, K.G.; Xuan, W.; Lu, T.D.; Zhang, W.; Chen, X. Accuracy enhancement of GPS time series using principal component analysis and block spatial filtering. Adv. Space Res. 2015, 55, 1316-1327. [CrossRef]

21. Li, W.W.; Shen, Y.Z.; Li, B.F. Weighted spatiotemporal filtering using principal component analysis for analyzing regional GNSS position time series. Acta Geod. Geophys. 2015, 50, 419-436. [CrossRef]

22. Yuan, L.G.; Ding, X.L.; Chen, W.; Simon, K.; Chan, S.B.; Hung, P.S.; Chau, K.T. Characteristics of daily position time series from the Hong Kong GPS fiducial network. Chin. J. Geophys. 2008, 51, 1372-1384. [CrossRef]

23. Hyvarinen, A.; Oja, E. Independent component analysis: Algorithms and applications. Neural Netw. 2000, 13, 411-430. [CrossRef]

24. Ming, F.; Yang, Y.X.; Zeng, A.M.; Zhao, B. Spatiotemporal filtering for regional GPS network in China using independent component analysis. J. Geod. 2017, 91, 419-440. [CrossRef]

25. Li, W.H.; Li, F.; Zhang, S.K.; Lei, J.T.; Zhang, Q.C.; Yuan, L.X. Spatiotemporal Filtering and Noise Analysis for Regional GNSS Network in Antarctica Using Independent Component Analysis. Remote Sens. 2019, 11, 386. [CrossRef]

26. He, X.X.; Bos, M.S.; Montillet, J.P.; Fernandes, R.; Melbourne, T.; Jiang, W.P.; Li, W.D. Spatial Variations of Stochastic Noise Properties in GPS Time Series. Remote Sens. 2021, 13, 4534. [CrossRef]

27. Zhang, J.; Bock, Y.; Johnson, H.; Fang, P.; Williams, S.; Genrich, J.; Wdowinski, S.; Behr, J. Southern California Permanent GPS Geodetic Array: Error analysis of daily position estimates and site velocities. J. Geophys. Res. Solid Earth 1997, 102, 18035-18055. [CrossRef]

28. Mao, A.L.; Harrison, C.G.A.; Dixon, T.H. Noise in GPS coordinate time series. J. Geophys. Res. Solid Earth 1999, 104, 2797-2816. [CrossRef]

29. Bogusz, J.; Klos, A. On the significance of periodic signals in noise analysis of GPS station coordinates time series. GPS Solut. 2016, 20, 655-664. [CrossRef]

30. Thomas, I.D.; King, M.A.; Bentley, M.J.; Whitehouse, P.L.; Penna, N.T.; Williams, S.D.P.; Riva, R.E.M.; Lavallee, D.A.; Clarke, P.J.; King, E.C.; et al. Widespread low rates of Antarctic glacial isostatic adjustment revealed by GPS observations. Geophys. Res. Lett. 2011, 38, L22302. [CrossRef]

31. Nield, G.A.; Barletta, V.R.; Bordoni, A.; King, M.A.; Whitehouse, P.L.; Clarke, P.J.; Domack, E.; Scambos, T.A.; Berthier, E. Rapid bedrock uplift in the Antarctic Peninsula explained by viscoelastic response to recent ice unloading. Earth Planet. Sci. Lett. 2014, 397, 32-41. [CrossRef]

32. Martin-Espanol, A.; King, M.A.; Zammit-Mangion, A.; Andrews, S.B.; Moore, P.; Bamber, J.L. An assessment of forward and inverse GIA solutions for Antarctica. J. Geophys. Res. Solid Earth 2016, 121, 6947-6965. [CrossRef] [PubMed]

33. Liu, B.; King, M.; Dai, W.J. Common mode error in Antarctic GPS coordinate time-series on its effect on bedrock-uplift estimates. Geophys. J. Int. 2018, 214, 1652-1664. [CrossRef]

34. Whitehouse, P.L.; Bentley, M.J.; Le Brocq, A.M. A deglacial model for Antarctica: Geological constraints and glaciological modelling as a basis for a new model of Antarctic glacial isostatic adjustment. Quat. Sci. Rev. 2012, 32, 1-24. [CrossRef]

35. Whitehouse, P.L.; Bentley, M.J.; Milne, G.A.; King, M.A.; Thomas, I.D. A new glacial isostatic adjustment model for Antarctica: Calibrated and tested using observations of relative sea-level change and present-day uplift rates. Geophys. J. Int. 2012, 190, 1464-1482. [CrossRef]

36. Geruo, A.; Wahr, J.; Zhong, S. Computations of the viscoelastic response of a 3-D compressible Earth to surface loading: An application to Glacial Isostatic Adjustment in Antarctica and Canada. Geophys. J. Int. 2013, 192, 557-572. [CrossRef]

37. Paulson, A.; Zhong, S.J.; Wahr, J. Limitations on the inversion for mantle viscosity from postglacial rebound. Geophys. J. Int. 2007, 168, 1195-1209. [CrossRef]

38. Bar-Sever, Y.E.; Kroger, P.M.; Borjesson, J.A. Estimating horizontal gradients of tropospheric path delay with a single GPS receiver. J. Geophys. Res. Solid Earth 1998, 103, 5019-5035. [CrossRef]

39. Blewitt, G. Carrier Phase Ambiguity Resolution for the Global Positioning System Applied to Geodetic Baselines up to $2000 \mathrm{~km}$. J. Geophys. Res.-Solid Earth Planets 1989, 94, 10187-10203. [CrossRef] 
40. Bertiger, W.; Desai, S.D.; Haines, B.; Harvey, N.; Moore, A.W.; Owen, S.; Weiss, J.P. Single receiver phase ambiguity resolution with GPS data. J. Geod. 2010, 84, 327-337. [CrossRef]

41. Beavan, J. Noise properties of continuous GPS data from concrete pillar geodetic monuments in New Zealand and comparison with data from U.S. deep drilled braced monuments. J. Geophys. Res. Solid Earth 2005, 110, B08410. [CrossRef]

42. Bos, M.S.; Fernandes, R.M.S.; Williams, S.D.P.; Bastos, L. Fast error analysis of continuous GNSS observations with missing data. J. Geod. 2013, 87, 351-360. [CrossRef]

43. Schneider, T. Analysis of incomplete climate data: Estimation of mean values and covariance matrices and imputation of missing values. J. Clim. 2001, 14, 853-871. [CrossRef]

44. Hyvarinen, A. Fast and robust fixed-point algorithms for independent component analysis. IEEE Trans. Neural Netw. 1999, 10, 626-634. [CrossRef]

45. Peres-Neto, P.R.; Jackson, D.A.; Somers, K.M. How many principal components? stopping rules for determining the number of non-trivial axes revisited. Comput. Stat. Data Anal. 2005, 49, 974-997. [CrossRef]

46. Agnew, D.C. Realistic Simulations of Geodetic Network Data: The Fakenet Package. Seismol. Res. Lett. 2013, 84, 426-432. [CrossRef]

47. Akaike, H. New Look at Statistical-Model Identification. IEEE Trans. Autom. Control 1974, 19, 716-723. [CrossRef]

48. Groh, A.; Ewert, H.; Scheinert, M.; Fritsche, M.; Rulke, A.; Richter, A.; Rosenau, R.; Dietrich, R. An investigation of Glacial Isostatic Adjustment over the Amundsen Sea sector, West Antarctica. Glob. Planet. Chang. 2012, 98-99, 45-53. [CrossRef]

49. Barletta, V.R.; Bevis, M.; Smith, B.E.; Wilson, T.; Brown, A.; Bordoni, A.; Willis, M.; Khan, S.A.; Rovira-Navarro, M.; Dalziel, I.; et al. Observed rapid bedrock uplift in Amundsen Sea Embayment promotes ice-sheet stability. Science 2018, 360, 1335-1339. [CrossRef]

50. Schroder, L.; Horwath, M.; Dietrich, R.; Helm, V.; van den Broeke, M.R.; Ligtenberg, S.R.M. Four decades of Antarctic surface elevation changes from multi-mission satellite altimetry. Cryosphere 2019, 13, 427-449. [CrossRef]

51. Zhang, B.J.; Wang, Z.M.; Li, F.; An, J.C.; Yang, Y.D.; Liu, J.B. Estimation of present-day glacial isostatic adjustment, ice mass change and elastic vertical crustal deformation over the Antarctic ice sheet. J. Glaciol. 2017, 63, 703-715. [CrossRef]

52. Dziewonski, A.M.; Anderson, D.L. Preliminary Reference Earth Model. Phys. Earth Planet. Inter. 1981, 25, 297-356. [CrossRef]

53. Sasgen, I.; Konrad, H.; Ivins, E.R.; Van den Broeke, M.R.; Bamber, J.L.; Martinec, Z.; Klemann, V. Antarctic ice-mass balance 2003 to 2012: Regional reanalysis of GRACE satellite gravimetry measurements with improved estimate of glacial-isostatic adjustment based on GPS uplift rates. Cryosphere 2013, 7, 1499-1512. [CrossRef]

54. An, M.J.; Wiens, D.A.; Zhao, Y.; Feng, M.; Nyblade, A.A.; Kanao, M.; Li, Y.S.; Maggi, A.; Leveque, J.J. S-velocity model and inferred Moho topography beneath the Antarctic Plate from Rayleigh waves. J. Geophys. Res. Solid Earth 2015, 120, 359-383. [CrossRef]

55. Van der Wal, W.; Whitehouse, P.L.; Schrama, E.J.O. Effect of GIA models with 3D composite mantle viscosity on GRACE mass balance estimates for Antarctica. Earth Planet. Sci. Lett. 2015, 414, 134-143. [CrossRef]

56. King, M.A.; Bingham, R.J.; Moore, P.; Whitehouse, P.L.; Bentley, M.J.; Milne, G.A. Lower satellite-gravimetry estimates of Antarctic sea-level contribution. Nature 2012, 491, 586-589. [CrossRef]

57. Nield, G.A.; Whitehouse, P.L.; King, M.A.; Clarke, P.J. Glacial isostatic adjustment in response to changing Late Holocene behaviour of ice streams on the Siple Coast, West Antarctica. Geophys. J. Int. 2016, 205, 1-21. [CrossRef]

58. Wolstencroft, M.; King, M.A.; Whitehouse, P.L.; Bentley, M.J.; Nield, G.A.; King, E.C.; McMillan, M.; Shepherd, A.; Barletta, V.; Bordoni, A.; et al. Uplift rates from a new high-density GPS network in Palmer Land indicate significant late Holocene ice loss in the southwestern Weddell Sea. Geophys. J. Int. 2015, 203, 737-754. [CrossRef]

59. Zhao, C.; King, M.A.; Watson, C.S.; Barletta, V.R.; Bordoni, A.; Dell, M.; Whitehouse, P.L. Rapid ice unloading in the Fleming Glacier region, southern Antarctic Peninsula, and its effect on bedrock uplift rates. Earth Planet. Sci. Lett. 2017, 473, 164-176. [CrossRef]

60. Heeszel, D.S.; Wiens, D.A.; Anandakrishnan, S.; Aster, R.C.; Dalziel, I.W.D.; Huerta, A.D.; Nyblade, A.A.; Wilson, T.J.; Winberry, J.P. Upper mantle structure of central and West Antarctica from array analysis of Rayleigh wave phase velocities. J. Geophys. Res. Solid Earth 2016, 121, 1758-1775. [CrossRef]

61. Boening, C.; Lebsock, M.; Landerer, F.; Stephens, G. Snowfall-driven mass change on the East Antarctic ice sheet. Geophys. Res. Lett. 2012, 39, L21501. [CrossRef] 